\title{
Advantages and disadvantages of rail transportation as perceived by passengers: A qualitative and quantitative study in the Czech Republic
}

\author{
Martina Trepáčová, Veronika Kurečková, Petr Zámečník, Pavel Řezáč \\ Centrum dopravního výzkumu, v.v.i., Líšeňská 33a, Brno 636 00, Česká republika
}

\begin{abstract}
:
Introduction

Public transport is an important element of sustainable mobility. Rail travel is a traditional mode of transport in the Czech Republic. Its many benefits include positive environmental and safety aspects and the reduction of traffic jams. The choice of transport mode is acomplex process involving both rational and irrational motives. More effective promotion of rail transport requires a better understanding of how it is perceived by potential users. This research identifies the key factors perceived as advantages and disadvantages of rail transportation in the Czech Republic.
\end{abstract}

\section{Methods}

In the first phase, an interview framework was constructed and used for in-depth interviews in 35 households using the interpretative phenomenological approach (IPA). These interviews defined the key preferences and barriers for using the train. Data collection was complemented by a quantitative online survey of 405 respondents who rarely used the train.

\section{Results}

In the qualitative part of the research, several topics arose from the interviews. Respondents perceive the following aspects as advantages when travelling by train: comfort, the train as a space for social interaction, the view, transportation without worry, and seat reservations. Disadvantages include: crowding, organization of the rail system, low number of trains, delays, train routes, boarding and exiting the train, and luggage transportation. Finances and safety are seen both as advantages and disadvantages of rail travel.

The results of the quantitative part of the research show respondents appreciate that they do not have to pay attention or control the actual process of travelling ( $n=232 ; 57.3 \%$ ) as compared to using an automobile. They also perceive the ability to move around in the train ( $n=153,37.8 \%)$ and the comfort during the journey ( $n=152,37.5 \%)$ as advantages. On the other hand they see as disadvantages delays ( $n=192$, $47.4 \%)$, transfers between modes of travel ( $n=177$, 43.7\%) and poor access to some destinations ( $n=161$, $39.8 \%)$.

\section{Conclusions}

Travelling is a daily part of many people's lives, and it is desirable to create conditions that simplify this process and make rail transportation accessible to as many passengers as possible across society, whether for individuals, groups, or persons with reduced mobility. This research identified areas that could influence decision-making for the use of rail transportation.

Keywords: Rail transportation; mode choice; advantages; disadvantages; train; barriers; crowding

\section{INTRODUCTION}

Public transport is an important element of sustainable mobility, and rail travel is a traditional mode of public transport in the Czech Republic. Its many benefits include positive environmental and safety aspects and the reduction of traffic jams. Rail systems in the Czech Republic and in Western Europe provide reliable, fast, and fairly frequent connections. However, the choice of transport mode includes numerous other factors like distance, route, costs, safety, travel restrictions during the journey, and luggage limits (Cheng, 2010). To increase the use of public transportation, it is necessary to identify and describe both the factors that support the willingness to use the train and some possible strategies to reduce the reluctance to use it (Murray, Davis, Stimson, \& Ferreira, 1998). The aim of our research is to identify and explore advantages and disadvantages that passen- 
gers associate with rail transportation. The knowledge of passengers' perceptions of advantages and disadvantages can help better understand the motivation of passengers. The motivation to use the train is a rather complex issue that includes factors like individual needs, expectations and concerns about the organization of the transportation, train vehicles, the rail transportation system, and train station infrastructure (Blainey, Hickford, \& Preston, 2012). The travel environment, which includes both physical and social elements, is another important component. For public transportation, these elements include seat availability, ride smoothness, spaciousness, air conditioning, lighting, cleanliness, spatial layout, furniture, and facility design (Li, 2003). Train station accessibility can also be a decisive factor. All of these elements can have both positive and negative effects on users' motivation to choose rail travel (Cheng, 2010).

Public transportation systems are considered to be a useful solution for the growing demand for mobility (Hine \& Scott 2000; Li, 2003). With more people using public transportation, the number of associated difficult and stressful situations is increasing (Cox, Houdmont, \& Griffiths, 2006). Stressful and unpleasant situations affect the personal comfort of passengers and significantly influence their transportation choices. Numerous studies have shown that average door-to-door journey times by public transport are longer than those by car (Accent, 2009; Eriksson, Friman, \& Gärling, 2008; Hine \& Scott, 2000), and this can be a significant barrier to mode shift. Travel mode choices are always affected by emotions, and a number of key factors are more subjective than objective. Subjective or irrational motives are often reflected in the assessment of seemingly objective factors (e.g. car dependence, personal security, comfort). It should also be noted that transportation users cannot always consider all of their feelings and needs (Cheng, 2010). Travelling is potentially stressful and a source of anxiety, so travel conditions play a key role (Novaco et al., 1979). For example, Blainey et al. (2012) divide barriers to rail travel into three factors: "hard," "soft," and "complementary". They state that travelers are unlikely to consider these barriers individually; instead they see them as a package, which can make it difficult to identify which barriers are the most significant. Hard barriers include travel time, reliability, service frequency and timetabling, interchange, network limitations, cost, station access and egress, ticketing complexity, structural car dependence, land-use pat- terns, government policy, safety, and inherent unsuitability of rail for trips. Among soft barriers are such factors as inaccurate perceptions, conscious car dependence, convenience and freedom, lack of control, journey planning requirements, information accessibility, station facilities, cleanliness and maintenance, personal security, staff presence, comfort, crowding, other passengers, and the image of public transport. Among complementary barriers they include trip chaining, habit, individuality, age, health and disability, ethnicity, faith and culture, goods and baggage, locational preferences, influence of employers, suboptimal market prices, and weather.

Passenger anxiety can also be triggered by different segments in the rail system service chain. Causes that can possibly lead to passenger anxiety include the following components: access to the rail system; the train station; the platform; the atmosphere in the train car; and train service. The journey itself should also be considered, including the service provided, the necessity to change trains or use additional modes of transportation, the need to search for an exit from the destination station, and the need to continue on local transportation to reach the final destination (Cheng, 2010). In practice, the results of studies on this topic can serve as a reference for rail system operators to help improve the services provided and the physical environment of train stations (Cheng, 2010).

Some train connections do not meet present day expectations for hygiene and equipment. Noisy train cars are more common on local lines and, in general, in countries with a lower culture of rail transport; this can be a specific source of anxiety for passengers (Ljungberg \& Neely, 2007; Stradling, Carreno, Rye, $\&$ Noble, 2007). On the other hand, people who do not often use trains are poorly acquainted with the increasing standards of technical equipment, hygiene, and the comfort of contemporary vehicles. Travelling by train includes more interaction with other passengers, especially in a coupe, and with staff than is the case with individual transportation. Crowded vehicles are also associated with a number of subjectively unpleasant feelings, like stress and anxiety (Turner et al. in Evans \& Wener, 2007). Studies suggest that the level of anxiety increases with the number of fellow passengers (Cox et al., 2006; Cheng, 2010). The disturbance of personal space is, therefore, a greater stressor than the density of the seating itself (Evans $\&$ Wener, 2007). Higher density also increases the likelihood of physical and social contact, which involves unwanted and unpredictable interactions. 
It takes more time to travel by train because timerelated costs are associated with rail travel and the transfer to the train station, as well as, in some cases, time constraints associated with the low frequency of train connections. Train delays further slow travel and cause high levels of anxiety and discomfort (Martin \& Corl, 1986; Thum, Boucsein, Kuhmann, \& Ray, 1995).

Various groups of passengers have different feelings and preferences in relation to rail transportation (Cheng, 2010; Lynch \& Atkins, 1988). Passengers who travel alone have more anxiety than passengers who travel with companions. Women are noticeably more anxious than men when travelling at night. In fact, results show that concern about the safety of travelling at night is a major factor for women (Lynch $\&$ Atkins, 1988). On the other hand, women experience less anxiety than men in situations where insufficient timetable information is provided (e.g., obsolete information, poor accessibility of information) (Cheng, 2010).

The perceptions of train transportation, including preferences and motivations, are personal for each individual traveler. Insights into individual attitudes can help to understand travel behavior (Cheng, 2010). The empirical results of the Cheng (2010) study suggest that passengers associate anxiety most strongly with overcrowding, followed by delays, the accessibility of a train station, finding the right train or platform, and the difficulty of transfers.

Previous research has shown that there are many factors of varying importance that influence the decision to travel by train. The aim of this study is to identify the advantages and disadvantages of rail travel perceived by the adult population of the Czech Republic that might influence passengers' motivation to use the train as a mean of transport. It is important to identify these factors because they can serve as the basis for adjusting travel conditions in the Czech Republic in order to make rail travel more attractive for more travelers. Making rail transportation attractive and popular would be a helpful factor in promoting sustainable mobility among individual travel decisions.

\section{METHODOLOGY}

Several data collection methods were used to ensure a sufficiently broad framework in order to obtain relevant data and define the main barriers to pas- senger rail transportation, including in-depth interviews within selected population groups, conducting focus groups, and administering a quantitative questionnaire.

\subsection{Qualitative study}

A pilot study included an interview with open-ended questions about rail transportation. In total, six respondents with different socio-demographic characteristics and preferred modes of transportation were interviewed. Based on the results of the literature review and these interviews, the structure for qualitative questioning was established for a larger sample of respondents.

We applied an interpretative phenomenological analysis (IPA) approach in the analysis of interviews. The aim is to formulate topics that allow us to understand how a person shapes the meaning of his experience, which in turn allows us to understand individual events or processes (Smith, Flowers, \& Larkin in Řiháček, Čermák, \& Hytych, 2013). We chose five steps for the qualitative interviews: basic questioning, detailed specification of subtopics, commentary on the basic list of barriers, space for additional comments and questions, and sociodemographic characteristics.

The interviews were conducted by four interviewers, one of whom was identified as the coordinator. The coordinator monitored the distribution of the respondents to each interviewer, the methodology (e.g., comprehensive training of interviewers), and the collection of records. The preparation and implementation of the qualitative questioning began by addressing potential respondents. Respondents were selected to ensure as diverse as possible a sample of the selected sociodemographic variables and factors influencing travel (e.g., gender, age, education, socioeconomic status, size of city or village of residence, possession of a driving license, ownership or availability of transportation, the reason for travelling by train, frequency of train travel). We did not intend to reflect the socio-demographic structure of the population of the Czech Republic, but rather to obtain the widest possible information base for this topic.

The original schedule included 30 respondents, with the possibility that more respondents could be added to ensure the theoretical saturation of the sample. Overall, 35 individual in-depth interviews were conducted. The semi-structured questionnaire was chosen as the most appropriate form for collecting 
qualitative data for the predetermined areas. The semi-structured interview form was chosen mainly because it allowed for the possibility to drill further into a problem, to provide space for respondents to express subjective opinions, and to allow for flexibility in data acquisition. The main topics were specified, but the order of the questions was determined by the researcher according to the course and circumstances of the interview. Some interviews were recorded on a dictaphone, others were handwritten, according to the respondents' preferences.

Based on the interviews, the focus group was conducted to clarify and refine the information gathered from the interviews. Six respondents participated in the focus group, three women and three men. All had different socio-demographic characteristics and preferred modes of transportation.

\subsection{Quantitative study}

Based on the outcomes of both the qualitative interviews and the focus group, a short internet (omnibus) survey was created to assess the structure of perceived advantages and disadvantages of rail transportation within a larger sample of respondents. The internet survey was conducted by a data collection company. The interviews corresponded to the demographic distribution of the Czech Republic's adult population. A structured, standardized questionnaire was chosen for the quantitative internet survey. The aim was to assess the importance of factors identified in the qualitative part of the research with a larger sample of respondents. $\mathrm{Al}$ together, 405 respondents from throughout the Czech Republic participated in the survey. The purpose was to determine what discouraged people from using the train as a mode of transport. For this reason, a filtering question was chosen to establish the frequency of train travel. Respondents continued in the survey after indicating that they travelled by train at least once a year, less often than once a year, or never. Overall, the questionnaire had five groups of questions. Except for the last question, all of the questions asked respondents to select answers from the following options: "yes," "no," or "do not know". The first question investigated the means of transport used by respondents in the previous year (e.g., bicycle, public transportation, bus, automobile, train, airplane). The second question focused on the factors that influenced the means of transportation the respondents would use (e.g., travel destination, time spent on the journey, fare, distance, the number of transfers, the amount of luggage, the number of passengers in the group, comfort, weather, mood). The third question asked the respondents how they perceived travelling by train (e.g., speed, comfort, the opportunity to go for a walk within the vehicle, the opportunity to work while travelling, the possibility for refreshment, the ability to transport a stroller, more comfortable travelling with a child, no need to concentrate on the operation of the vehicle, the view, safety, air conditioning, luggage transport). The penultimate question concentrated on the disadvantages associated with travelling by train (e.g., delays, discomfort in the train car, slowness of transport, the number of passengers, long travel intervals in the evening and at night, the necessity to get to the train station, the fare, poor accessibility to some destinations, the loss of privacy, a fixed timetable). The last question asked whether the respondents would use the train more often if the conditions of an offered list of options were fulfilled (e.g., a timetable that would suit them better, easy access to the train station, barrier-free access to the platforms and the train, an improved pro-customer approach, a clear pricing policy, lower fares, reliability, parking in the vicinity of the train station, suitable conditions for travelling with a stroller, comfort on trains, a high level of information about delays).

\section{RESULTS}

\subsection{Qualitative study}

Although selection of the mode of transportation is a complex process, we hold that some factors are crucial. Advantages as well as disadvantages of train use are fairly complex and reflect individual needs, expectations, and concerns; the organization of the rail system, train vehicles, station infrastructure, and the atmosphere of the surrounding location; even the trip to the train station is part of rail transportation, and the accessibility of the train station can be considered. For example, individual rail transportation can include the availability of seating, the route of the journey, air conditioning, lighting, cleanliness, and the layout of the train. All of these elements can be perceived both as advantages and disadvantages. The main topics which emerged from the interviews are described in the following text.

\subsubsection{Advantages of rail transportation}

3.1.1.1 Finances

The price of train tickets is still an important factor for a number of interviewees. It increases in importance 
when more frequent rail travel is necessary. Trains in the Czech Republic are usually more expensive than bus transport. Many respondents, however, remarked that trains in the Czech Republic are still significantly cheaper than those abroad, especially in Western Europe. Some respondents, usually those who regularly use the train and seem satisfied, have a fairly accurate knowledge of the available discounts and benefits. Others usually have incorrect knowledge or none at all. If a passenger travels alone, the train is usually cheaper than travelling by automobile. Larger groups may not be convenient for train travel. Thus, group discounts may be a motivation. However, according to some respondents, pricing policy should be simple and comprehensible, and discounts should be offered automatically.

\subsubsection{Comfort}

Passengers appreciate that the cleanliness and comfort of train cars have been improving dramatically. However, many trains are still old and unattractive. Old train cars are less comfortable, with noisy, bumpy rides, and lack air conditioning. The modernization and renewal of rolling stock is, in any case, an important factor to increase the attractiveness of passenger rail transportation, improve its public image, and burnish the prestige of the rail transportation system. Most interviewees say that the quality and comfort of the vehicles have increased their tendency to travel by train. Respondents appreciate the possibility to walk around in the train to stretch their legs, and some mention that the seats are more spacious and comfortable than those on buses. Respondents also appreciate the greater quiet of travel, both through the introduction of new vehicles and the upgraded train infrastructure. One problem, especially for passengers with a physical disability or with a lot of luggage, is getting on and off the train. Most train cars are not barrier-free and the embarking and disembarking of handicapped passengers is complicated and usually requires assistance. The absence of a mobile telephone signal in some sections of the track is negatively perceived by passengers. Travelers who are used to working on the train may consider this to be a complication. However, the telephone signal itself is not a key motivation for choosing the mode of transportation. Dining cars are becoming more popular. In the event that the train lacks a dining car or it is full, passengers appreciate the opportunity to buy food from stewards, as well as the ability to consume their own food. The train of- fers space to relax, read, eat and drink in the dining car, while listening to music, and watching movies on a PC or mobile phone. Compared to the bus, the train is more comfortable, quieter, and passengers suffer less often from kinetosis (i.e., motion sickness). The quieter train ride and the well-designed interior make it easier for passengers to focus on work. That is why the train is favored by people who do not want to waste time driving a car and want to work while travelling. In this context, the equipment in train cars is important - it should ideally contain a small table, or at least power sockets to charge PCs and mobile phones. Undoubtedly, the train should offer Wi-Fi.

\subsubsection{Trains as a space for social interaction}

The interior of the train allows for close contact with other passengers. Sometimes this can be demotivating and intrusive; however, especially if the passenger is travelling with a close friend or family member, it can be a good opportunity to talk. Some respondents mentioned that they like to travel with the whole family because members have more time and they can share the travel experience. Some interviewees said they meet with friends on the train instead of going to a restaurant together.

\subsubsection{View}

A rather surprising result of the qualitative survey was the importance of the view of the landscape. Usually the train tracks go through areas that are hard to see from the road and train routes offer a different point of view and more contact with nature. Many respondents mentioned that watching the landscape was one of their motivational elements, which is not only fun in itself but also a way to relax.

\subsubsection{Transportation without worry}

When driving an automobile, one has always to be ready to react to road situations, have a planned route, take responsibility for the entire course of the journey, and be prepared for complications. Train passengers do not have these concerns. This carefree feeling is appreciated on longer routes and when the weather conditions are bad, which would add stress to an automobile trip. Respondents also appreciated the fact that, unlike a bus driver, the train engineer is not as visible on the train. Passengers do not have to (and cannot) monitor the engineer's activity, which for most of them is rather soothing and comfortable. 


\subsubsection{Transportation safety}

Respondents consider trains to be among the safest types of vehicles. Most passengers are aware of the safety of rail travel, and for some, this is one of their reasons for preferring the train. The choice of a train as a safe means of transportation is more pronounced in periods of extreme weather conditions, especially snow. Personal safety on the train, however, is a completely different issue. Long-distance trains from Slovakia or trains on remote routes within the Czech Republic were mentioned as causes for concern. Night travel was perceived as more risky. Women reported that they felt more vulnerable (e.g., fear of harassment, risk of being robbed) than men. However, in general, the train station is perceived to be a considerably riskier environment than being on the train itself. Some interviewees do not ride trains just because of the unpleasant or dangerous environment of train stations and their surroundings.

\subsubsection{Seat reservations}

Seat reservations are a potential issue. Some passengers appreciate that they can book their seat in advance. Others like that they can board a train without planning. In addition, if a passenger sits in a coupe with people whom they do not like, their ability to change to a different seat is limited.

\subsubsection{Disadvantages of rail transportation \\ 3.1.2.1 Crowding}

Almost all respondents reported that they found it unpleasant to travel in a crowded vehicle. For some, the proximity of other people in the vehicle was a significant demotivating factor. The absence of seating and the need to spend time in the immediate vicinity of other people can be completely discouraging to some. However, more people on the train can also be a positive factor (e.g., at night, in problematic trains where the presence of other people reinforces the subjective feeling of safety, especially in open-space cars). A separate topic is the preference for travelling in open-space train cars, compared to enclosed-coupe train cars. It turns out that passenger preferences are diverse. When travelling in a coupe, passengers appreciate greater privacy and the opportunity to travel with friends, colleagues, and family. Some of the interviewees used the coupe to strike up conversations with strangers.

\subsubsection{Organization of the rail system}

Orientation amidst the possibilities for rail transportation as well as in the area of train stations and trains are important problematic elements that directly influence the motivation to choose rail transportation. The key factor is the availability and clarity of information (e.g., timetable, orientation on train platforms and in the train cars, knowledge of rules and restrictions). Different target groups use different channels for information. Younger travelers use the internet, particularly mobile applications. Older passengers are more dependent upon the information boards located in all relevant locations.

\subsubsection{Financial cost}

While many respondents admit that train fares in the Czech Republic are cheaper than in most Western European countries, the train is often more expensive than the bus and, if travelling with several people, it is more expensive than sharing the cost of an automobile. Travel costs are also high when the destination is abroad.

\subsubsection{Low number of trains, delays, train route}

Although the rail network in the Czech Republic is relatively dense, it does not reach all localities and its density is lower than the road and highway network. The vast majority of passengers have to combine the train with other means of transport, including walking (sometimes relatively long distances), public transportation, automobile, or bus. Insufficient interconnection with other modes of transportation is one of the major reasons why many travelers do not use the train. Additionally, the train often does not reach specific locations; complications on the track increase the risk of missing connections; and delays, in general, are a significant demotivating factor.

\subsubsection{Boarding and exiting the train and luggage transportation}

Getting on and off trains is inconvenient and dangerous, especially for passengers with physical disabilities, children, and seniors. It is also difficult to move luggage and other carry-ons (e.g., strollers, bicycles). Problematic movement through the train station is usually associated with problematic movement within the vehicle. People with physical disabilities cannot board most train cars without assistance, which can complicate traffic and can be demotivating. Stairs and high steps to enter and exit the train are also obstacles for baby strollers. Luggage is a problem when travelling by public transportation and by train. For passengers, it is often inconvenient and almost impossible to maneuver in the vehicle with their 
luggage and then to ensure its safe storage during the journey.

\subsubsection{Safety}

While the train is generally a safe means of transportation, the issue of personal safety in the vehicle is questionable. However, subjective feelings are often of greater importance than the actual risks of a given situation. The feeling of danger in train cars is felt more often by women than men, and it is more pronounced at night, especially in certain locations. Respondents perceive risk at night on international trains from Slovakia, and in remote locations within the Czech Republic. The lack of staff on the train and the lack of surveillance equipment contribute to the feeling of danger. More serious perceptions of danger are related to train stations and their vicinity. Train stations are often located in areas that attract a number of problems that can ultimately be a major demotivating factor for potential travelers.

\subsection{Quantitative study}

The sample of respondents consisted both of men $(\mathrm{n}=210 ; 51.9 \%)$ and women $(\mathrm{n}=195 ; 48.1 \%)$. The total number of respondents was 405 . The mean age was 48.5 years old $(S D=15.3$; $\mathrm{Med}=49 ; \mathrm{Mo}=67)$. The youngest respondent was 18 years old and the oldest respondent was 79 years old (Table 1 ).

Table 1: Representation of age groups

\begin{tabular}{llc}
\hline & $\mathbf{n}$ & \% \\
\hline $18-24$ & 25 & 6.2 \\
$25-34$ & 66 & 16.3 \\
$35-44$ & 80 & 19.8 \\
$45-54$ & 79 & 19.5 \\
$55-64$ & 69 & 17.0 \\
65 and over & 86 & 21.2 \\
\hline Total & 405 & 100 \\
\hline
\end{tabular}

Table 2: Highest educational level

\begin{tabular}{lcc}
\hline & $\mathbf{n}$ & $\mathbf{\%}$ \\
\hline Elementary & 63 & 15.6 \\
High school & 286 & 70.6 \\
University & 56 & 13.8 \\
\hline Total & 405 & 100 \\
\hline
\end{tabular}

Table 2 shows that for the largest proportion of respondents, completion of high school was their highest level of education.

The sample included respondents who travel by train at least once a year, less frequently than once a year, and never (Table 3).

Table 3: Responses to the question: How often do you travel by train?

\begin{tabular}{lcc}
\hline & $\mathbf{n}$ & \% \\
\hline At least once a year & 150 & 37.0 \\
Less than once a year & 188 & 46.5 \\
Never & 67 & 16.5 \\
\hline Total & 405 & 100 \\
\hline
\end{tabular}

Table 4 shows the means of transportation that respondents used in the preceding year. Most used an automobile $(\mathrm{n}=374 ; 92.3 \%)$ or public transportation $(n=280 ; 69.1 \%)$. About a third of the respondents used a train $(n=136 ; 33.6 \%)$. Respondents mentioned the use of a motorcycle $(n=7)$, scooter, boat, taxi, and private ambulance among the other means of transport.

Table 4: Responses to the question: What means of transportation have you used in the last year?

\begin{tabular}{lcc}
\hline & $\mathbf{n}$ & $\mathbf{\%}$ \\
\hline Bicycle & 179 & 44.2 \\
Public transportation (tram, trolleybus, bus) & 280 & 69.1 \\
Long-distance bus & 108 & 26.7 \\
Automobile & 374 & 92.3 \\
Train & 136 & 33.6 \\
Airplane & 67 & 16.5 \\
Other & 7 & 1.7 \\
\hline $\mathrm{N}=405$ & & \\
\hline
\end{tabular}

Travel destination $(\mathrm{n}=237 ; 58.5 \%)$ and comfort during the journey $(n=233 ; 57.5 \%)$ are the most important factors for choosing the means of transportation. Actual mood $(n=51 ; 12.6 \%)$ was the least important factor (Table 5). Other factors included in the decision process were cost, accessibility, ecological concerns, and age. 
Table 5: Answers to the question: Which factors play a role in deciding which means of transportation you choose?

\begin{tabular}{lcc}
\hline & $\mathbf{n}$ & $\mathbf{\%}$ \\
\hline Travel destination & 237 & 58.5 \\
Duration of the journey & 186 & 45.9 \\
Cost & 135 & 33.3 \\
Distance & 207 & 51.1 \\
Number of transfers to other trains & 91 & 22.5 \\
The amount of luggage & 125 & 30.9 \\
The number of passengers travelling & 67 & 16.5 \\
with you & & \\
The number of connections between & 107 & 26.4 \\
modes of transportation & & \\
Comfort & 233 & 57.5 \\
Weather & 89 & 22.0 \\
Actual mood & 51 & 12.6 \\
Other & 10 & 2.5 \\
\hline $\mathrm{N}=405$ & & \\
\hline
\end{tabular}

Attention to travel (e.g., not having to operate the vehicle) was considered one of the main benefits of travelling by train $(\mathrm{n}=232 ; 57.3 \%)$. Respondents appreciated not having to pay attention or control the actual process of travelling, like they do when driving an automobile. The ability to walk in the train ( $\mathrm{n}=153 ; 37.8 \%)$, comfort during the journey $(\mathrm{n}=152 ; 37.5 \%)$, and the view from the window $(\mathrm{n}=132 ; 32.6 \%)$ were rated as approximately equal benefits (Table 6 ). Other advantages of travelling by train were good connections to city centers without needing to find a parking spot, avoid traffic congestion on the roads, and the opportunity to make new acquaintances.

Table 6: Answers to the question: Which of these factors do you consider to be advantages of travelling by train?

\begin{tabular}{lcc}
\hline & $\mathbf{n}$ & $\mathbf{\%}$ \\
\hline Speed & 57 & 14.1 \\
Comfort & 152 & 37.5 \\
Ability to walk in the train & 153 & 37.8 \\
Possibility to work & 61 & 15.1 \\
Available refreshment & 58 & 14.3 \\
Ability to carry a stroller & 19 & 4.7 \\
Comfortable travelling with children & 57 & 14.1
\end{tabular}

I don't have to concentrate on the

232

57.3

journey (as opposed to driving an automobile)

View from the window

132

32.6

Safety

$40 \quad 9.9$

Air conditioning

$18 \quad 4.4$

Luggage transport

$35 \quad 8.6$

Other

45

11.1

$\mathrm{N}=405$

Table 7: Responses to the question: What do you consider the disadvantages of travelling by train?

\begin{tabular}{lcc}
\hline & $\mathbf{n}$ & $\mathbf{\%}$ \\
\hline Delays & 192 & 47.4 \\
Discomfort in the train car & 29 & 7.2 \\
Transfers between modes of travel & 177 & 43.7 \\
Slow transportation & 76 & 18.8 \\
High number of passengers & 63 & 15.6 \\
Limited travel options in the evening & 51 & 12.6 \\
and at night & & \\
Necessity to travel to a train station & 138 & 34.1 \\
High fares & 108 & 26.7 \\
Poor accessibility of some destinations & 161 & 39.8 \\
Traffic closures (due to construction) & 137 & 33.8 \\
Loss of privacy & 54 & 13.3 \\
Predetermined timetable & 49 & 12.1 \\
Train does not go where I need it & 159 & 39.3 \\
Unsatisfactory surroundings of the train & 36 & 8.9 \\
station & & \\
Crowding & 60 & 14.8 \\
I don't feel safe on the train & 37 & 9.1 \\
Other & 20 & 4.9 \\
\hline N = 405 & & \\
\hline & & \\
\hline
\end{tabular}

The most frequently mentioned disadvantages of train travel were delays $(n=192 ; 47.7 \%)$, transfers between modes of travel $(\mathrm{n}=177 ; 43.7 \%)$, poor accessibility of some destinations $(\mathrm{n}=161 ; 39.8 \%)$, and the fact that the train does not go where respondents need ( $n=159 ; 39.3 \%)$ (Table 7$)$. The least important disadvantages were discomfort in the train car ( $\mathrm{n}=29 ; 7.2 \%)$, the unsatisfactory surroundings of the train station $(\mathrm{n}=36 ; 8.9 \%)$, and the feeling that 
Table 8: Answers to the question: Would you use the train more often if the following conditions were met?

\begin{tabular}{|c|c|c|c|c|c|c|}
\hline & \multicolumn{2}{|c|}{ Yes } & \multicolumn{2}{|c|}{ No } & \multicolumn{2}{|c|}{ Do not know } \\
\hline & $\mathrm{n}$ & $\%$ & $\mathrm{n}$ & $\%$ & $\mathrm{n}$ & $\%$ \\
\hline A timetable that would suit me better & 197 & 48.6 & 109 & 26.9 & 99 & 24.4 \\
\hline Easy access to the train station & 253 & 62.5 & 86 & 21.2 & 66 & 16.3 \\
\hline Barrier-free access to the platform and the train & 137 & 33.8 & 163 & 40.2 & 105 & 25.9 \\
\hline Better customer service & 185 & 45.7 & 102 & 25.2 & 118 & 29.1 \\
\hline Transparent pricing policy & 194 & 47.9 & 104 & 25.7 & 107 & 26.4 \\
\hline Lower fares & 277 & 68.4 & 68 & 16.8 & 60 & 14.8 \\
\hline Reliability & 266 & 65.7 & 81 & 20.0 & 58 & 14.3 \\
\hline Parking in the vicinity of the train station & 217 & 53.6 & 111 & 27.4 & 77 & 19.0 \\
\hline Suitable conditions for travelling with a stroller & 110 & 27.2 & 191 & 47.2 & 104 & 25.7 \\
\hline Comfort in trains & 256 & 63.2 & 84 & 20.7 & 65 & 16.0 \\
\hline High level of quality for announcements about delays & 199 & 49.1 & 110 & 27.2 & 96 & 23.7 \\
\hline Other & 7 & 1.7 & 1 & 0.2 & 3 & 0.7 \\
\hline $\mathrm{N}=405$ & & & & & & \\
\hline
\end{tabular}

there is a lack of safety on the train $(n=37 ; 9.1 \%)$. Other disadvantages respondents mentioned were the need to arrive early if they used a wheelchair, difficulty boarding a train, the old and dirty interiors of train cars, and the obligation to pay extra for a seat reservation.

The last question on the questionnaire focused on the factors that could contribute to more frequent use of the train (Table 8). The most important factor was lower fares $(n=277 ; 68.4 \%)$, followed by reliability $(\mathrm{n}=266 ; 65.7 \%)$ and comfort on the trains $(\mathrm{n}=256$; 63.2\%). Less important factors were easy wheelchair access to the platform and to the train $(n=137$; $33.8 \%)$ and suitable conditions for travelling with a stroller $(\mathrm{n}=110 ; 27.2 \%)$.

Respondents often perceive a number of aspects, only some of which are crucial to their decisionmaking. The mode of transportation is not always a rational decision because it involves a number of irrational factors, the person's general lifestyle, and the person's worldview. Travel destination and time spent on the journey are considered to be important factors. Respondents also appreciated that they did not have to concentrate on operating the vehicle. On the other hand, delays or transfers between modes of travel are considered to be major disadvantages of travelling by train. More than half of the respondents would appreciate lower fares and more reliability within the rail system.

\section{DISCUSSION}

The motivations, necessities, and expectations for train travel are personal for each individual passenger. Respondents often perceived a number of aspects. It seems obvious that advantages and disadvantages of the train, as perceived by the travelers, should play a key role in their decision-making process. However, in reality only a few of them might actually be crucial. The decision making process has a strong irrational dimension because a number of subjective factors, the person's general lifestyle, and the person's worldview all play a role in this process.

Our research, as well as previous knowledge (e.g. Blainey et al., 2012; Cheng, 2010), shows that many emotional aspects play a role in choosing the mode of transport and also in a person's perception of the advantages and disadvantages of the train.

When considering the train as a transport mode, the following attributes were mentioned as important: Price, comfort, space for social interaction, view, transportation without worry, transportation safety, seat reservations, crowding, organization of the rail system, financial cost, low number of trains, delays, train route, boarding and exiting the train and luggage transportation and safety.

Many of the aspects were perceived both as advantages and disadvantages. This shows the complexity of the decision-making process. For exam- 
ple, financial cost - the price of rail travel is low when compared to individual car transport or the train costs in most Western European countries. On the other hand, when compared with bus transport, the train seemed more expensive. Safety is another inconsistent aspect - the train is one of the safest transport modes, but night travelling, for example, especially on certain lines or in train stations, makes the travelers feel unsafe This is consistent with Lynch and Atkins (1988). Some respondents also felt uncomfortable in overcrowded trains (see Cox et al., 2006; Cheng, 2010), but on the other hand, travelling by train is perceived by others as an opportunity for social interaction.

The organization of transport and especially the reliability (and reduction of delays) seem to play an important role in the decision-making process. For example, Thum et al. (1995) showed association between high levels of anxiety and discomfort with train delays. However, the perception of time is subjective, depending both on individual limits and social norms. For future research, the perception of delay duration and timing should be investigated more deeply.

Travel destination, distance and overall comfort seem to play an important role in the decision making process. However, in reality people rarely consider all of these aspects rationally or as stated by Cheng (2010) irrational motives could be reflected as seemingly objective factors. Many respondents were relatively conservative in their choice of transportation mode. If they get used to a particular means of transportation, they do not like to change and usually they do not consider potential alternatives at all. Changes are most often made when the form of transportation to which they are accustomed cannot, for some reason, be used anymore.

This research has shown some crucial aspects of the attractiveness of rail transportation. However, some methodological concerns remain. The pre-defined basic structure of the questionnaire was considered appropriate when more than one interviewer conducted interviews with a defined group of respondents. The data obtained was then more comparable and easier to analyze. However, there is still the risk of interviewer bias. The issue should be investigated further. This research focused on passengers who travel by train sporadically. Further research should include passengers who use train more often. We also reflect that the quantitative part of the research has a rather informational character and serves as a basis for more detailed research with a larger sample that not only reflects the socio-demographic structure of the Czech population but also includes all passengers whether they travel by train on a daily basis, occasionally or never. Although the data from this research are not part of the article we consider it important to mention that we plan more advanced statistical analyzes of the data on larger sample from follow-up research.

\section{CONCLUSION}

Rail transportation is a significant element of sustainable mobility. Therefore, its subjective attractivity is a serious issue that may have a crucial impact on the mobility of the country. There are many issues related to rail transport (e.g., governmental financial support) that should be considered and thoroughly planned according to strategic priorities.

We have to consider that the position of rail transportation in the Czech Republic is unique. In the past, travelling by train was perceived as a less prestigious form of transportation, especially for people with a lower socio-economic status. The increasing level of comfort has led to a gradual reduction of this perception. In the future, it would be appropriate to further enhance the image of trains as fast, comfortable, and environmentally friendly, and as part of a modern lifestyle.

Various measures should be taken to further support rail transportation. One priority should be the further development of the user friendliness of trains - comfort and cleanliness, sufficient space, a variety of interiors, technical equipment, barrierfree space, various vehicle functions, the ability to relax, work, and actively spend free time, and the perception that the train has spaces for both privacy and social interaction.

The greater reliability and speed of rail transportation is another aspect that could help to increase its attractiveness. This would require further improvements to the infrastructure, as well as transportation control. One of the crucial issues is transportation connections and delays. This has become a serious problem, especially when passengers have to change trains. There are many measures that should be taken, especially: 1 . Realistic schedules that reflect the capacity of tracks; 2 . A reduction of unexpected incidents through better technical quality of the infrastructure and of vehicles and safety measures (e.g., prevention of trespassing); 3. Further improvements 
to the rail traffic control system, including technical background and the human resource system; and 4 . Intermodal connectivity.

Intermodal connectivity is a crucial aspect for the attractiveness of rail transportation. Other modes of transportation - urban transport, individual transport (i.e., automobiles, bicycles, walking) - should be easily accessible from the train. It is necessary for parking spaces, bus and urban transport stops, and pedestrian-friendly zones to be close to train stations. Automobile and bicycle rentals near the stations can be helpful. Easier transporting of bicycles and strollers on trains can help to make the intermodal connectivity smoother and more effective.

A change in public discourse is also necessary. The train should become an attractive mode of transportation representing a modern and healthy lifestyle. Therefore, trains should be presented as something more than just a simple means of transportation - as an indivisible part of healthy mobility and a healthy lifestyle. For the elderly, who perceive the train as a marginal mode of transportation for lower social classes, it should be presented as modern, comfortable, and classy.

It is certainly desirable to make rail transportation more attractive, but in many situations, other modes of transportation remain more suitable. We should consider the capacity of train tracks and the economic and environmental aspects that, in many places, make rail travel unsustainable. It is, therefore, crucial to define the strategic priorities for all regions according to both specific local requirements and the global situation.

Acknowledgements: This article was produced with the financial support of the Ministry of Transport within the programme of long-term conceptual development of research institutions on the research infrastructure acquired from the Operation Programme Research and Development for Innovations (CZ.1.05/2.1.00/03.0064).

The authors declare that they have no conflict of interest.

All procedures performed the study were in accordance with the ethical standards of the institutional committee of Transport Research Centre Czech Republic and with the 1964 Helsinki declaration and its later amendments or comparable ethical standards. Informed consent was obtained from all individual participants included in the study.

\section{REFERENCES}

Accent (2009). Perception towards integrated transport. London: Passenger Focus.

Blainey, S., Hickford, A., \& Preston, J. (2012). Barriers to passenger rail use: a review of the evidence. Transport Reviews, 32(6), 675-696.

Cheng, Y. H. (2010). Exploring passenger anxiety associated with train travel. Transportation, 37(6), 875-896.

Cox, T., Houdmont, J., \& Griffiths, A. (2006). Rail passenger crowding, stress, health and safety in Britain. Transportation Research Part A: Policy and Practice, 40(3), 244-258.

Eriksson, L., Friman, M., \& Gärling, T. (2008). Stated reasons for reducing work-commute by car. Transportation Research Part F, 11(6), 427-433.

Evans, G. W., \& Wener, R. E. (2007). Crowding and personal space invasion on the train: Please don't make me sit in the middle. Journal of Environmental Psychology, 27(1), 90-94.

Hine, J., \& Scott, J. (2000). Seamless, accessible travel: users' views of the public transport journey and interchange. Transport policy, 7(3), 217-226.

Li, Y. W. (2003). Evaluating the urban commute experience: A time perception approach. Journal of Public Transportation, $6(4), 3$.

Ljungberg, J. K., \& Neely, G. (2007). Stress, subjective experience and cognitive performance during exposure to noise and vibration. Journal of Environmental Psychology, 27(1), 44-54.

Lynch, G., \& Atkins, S. (1988). The influence of personal security fears on women's travel patterns. Transportation, 15(3), 257-277.

Martin, G. L., \& Corl, K. G. (1986). System response time effects on user productivity. Behaviour \& Information Technology, 5(1), 3-13.

Murray, A. T., Davis, R., Stimson, R. J., \& Ferreira, L. (1998). Public transportation access. Transportation Research Part D: Transport and Environment, 3(5), 319-328.

Novaco, R. W., Stokols, D., Campbell, J., \& Stokols, J. (1979). Transportation, stress, and community psychology. American Journal of Community Psychology, 7(4), 361-380.

Řiháček, T., Čermák, I., \& Hytych, R. (2013). Kvalitativní analýza textů: čtyři prístupy. Brno: Masarykova univerzita.

Stradling, S., Carreno, M., Rye, T., \& Noble, A. (2007). Passenger perceptions and the ideal urban bus journey experience. Transport policy, 14(4), 283-292.

Thum, M., Boucsein, W., Kuhmann, W., \& Ray, W. J. (1995). Standardized task strain and system response times in humancomputer interaction. Ergonomics, 38(7), 1342-1351. 